\section{Synthesis and Luminescent Properties of a New Yellowish-Orange Afterglow Phosphor $\mathrm{Y}_{2} \mathrm{O}_{2} \mathrm{~S}: \mathrm{Ti}, \mathrm{Mg}$}

\author{
Chia-Cheng Kang, ${ }^{\dagger}$ Ru-Shi Liu,,$+\dagger$ \\ J iin-Chyuan Chang, ${ }^{\ddagger}$ and Biing-J ye Lee
}

Department of Chemistry, National Taiwan University, Taipe 106, Taiwan, Republic of China, Physical Chemistry Section, Chemical Systems Research Division, Chung-Shan Institute of Science \& Technology, Lung-Tan, Tao-Yuan 325, Taiwan, Republic of China, and E pistar Corporation, Science-Based Industrial Park, Hsin-Chu 300, Taiwan, Republic of China

Received May 28, 2003

Revised Manuscript Received August 7, 2003

Luminescence that persists after the removal of the excitation is called afterglow or persistent phosphorescence. Material with the aftergl ow property can be used in many fields, including traffic signs, interior decoration, and light sources. The first record of persistent phosphorescent material is in the Song dynasty of China (11th century A.D.). ${ }^{1}$ In the miscellaneous notes by a Song monk, of which the title is Xiang-Shan Ye-Lu, there is a story about a long lasting phosphorescent painting. On the painting was a cow that appeared during the daytime as eating grass outsi de the pen, but at night as resting in it. The ink that was shown in the dark for a given duration after absorption of light is long lasting phosphorescent material.

In the 18th century, people in Europe synthesized afterglow phosphors by using sea shells and sulfur. ${ }^{2}$ In the beginning of the 20th century, the ZnS:Cu phosphor has been known as a long phosphorescent phosphor and used in a variety of applications. This phosphor shows green emissions peaking at $530 \mathrm{~nm}$, which suits the visual perception of the human eye very well. However, it is not bright enough for many applications and does not maintain its phosphorescence for more than a few hours. Therefore, to sustain phosphorescence, radioactive el ements, such as radium $\left({ }^{88} \mathrm{Ra}\right)$, tritium $\left({ }^{3} \mathrm{H}\right)$, and promethium ( $\left.{ }^{147} \mathrm{Pm}\right)$, were added to $\mathrm{ZnS}: \mathrm{Cu}$ phosphor. Such paints have been used for luminous watches and clocks. However, for safety and environmental considerations, there is a serious demand for the devel opment of a radioactive-free long phosphorescent phosphor at the present time.

In the 1960 s and early 1970s, the $\mathrm{SrAl}_{2} \mathrm{O}_{4}: \mathrm{Eu}^{2+}$ phosphor has been known to be a green phosphor with an emission peak at $520 \mathrm{~nm}$ due to $4 \mathrm{f}^{6} 5 \mathrm{~d}$ to $4 \mathrm{f}^{7}$ transition of europium ion $\left(\mathrm{Eu}^{2+}\right)$, and this phosphor is mainly for

\footnotetext{
* To whom correspondence should be addressed. E-mail: rsliu@ ntu.edu.tw.

+ National Taiwan University.

₹ Chung-Shan Institute of Science \& Technology.

$\S$ E pistar Corporation.

(1) Harvey, E. N. A History of Luminescence; American Philosophical Society, 1957.

(2) Shionoya, S.; Yen, W. M. Phosphor Handbook; Phosphor Research Society; CRC Press: Boca Raton, FL, 1998.
}

fluorescent lamp and cathode ray tube (CRT) applications. $^{3-6}$ In 1995, Matsuazawa et al. ${ }^{7,8}$ successfully synthesized a $\mathrm{Eu}^{2+}$ and dysprosium ions ( $\mathrm{Dy}^{3+}$ ) coactivated $\mathrm{SrAl}_{2} \mathrm{O}_{4}$ phosphor. After excitation by the UV light, it exhibits greater brightness, longer persistent green phosphorescence, and better chemical stability than that of the ZnS:Cu phosphor. Matsuazawa et al. ${ }^{7}$ suggested a mechanism for the afterglow phenomenon. Dy $^{3+}$ ion serves as a trap center, and long lasting phosphorescence is caused by the trapping and thermal release of holes at $\mathrm{Dy}^{3+}$ ions in the system.

Europium ion-doped $\mathrm{Y}_{2} \mathrm{O}_{2} \mathrm{~S}$ red-emitting phosphor has been used in the field of CMT (color monitor tube) and high-resolution CRTs (cathode ray tubes) because of the higher efficiency compared with europium-doped $\mathrm{Y}_{2} \mathrm{O}_{3}$ phosphor. However, until now, yellowish-orange afterglow phosphor with $\mathrm{Y}_{2} \mathrm{O}_{2} \mathrm{~S}$ compound as a host lattice structure has not been reported. In this study, a new yellowish-orange afterglow phosphor $\mathrm{Y}_{2} \mathrm{O}_{2} \mathrm{~S}$ :Ti, Mg was synthesized. Its I uminescent properties and mechanism were investigated.

$\left(\mathrm{Y}_{2-x-y} \mathrm{Ti}_{x} \mathrm{Mg}_{y}\right) \mathrm{O}_{2} \mathrm{~S}(\mathrm{x}=\mathrm{y}=0.01)$ phosphor was synthesized by solid-state reaction with $\mathrm{Y}_{2} \mathrm{O}_{3}, \mathrm{~S}, \mathrm{TiO}_{2}$, and $\mathrm{MgO}$ as raw materials. Sodium carbonate $\left(\mathrm{Na}_{2} \mathrm{CO}_{3}\right)$ was added as a flux. The molar ratio of $\mathrm{Y}: \mathrm{Ti}: \mathrm{Mg}: \mathrm{S}$ is 1.98:0.01:0.01:6, respectively. Stoichiometric mixtures of highly pure raw materials were homogeneously mixed and sintered at high-temperature ranging from 900 to $1200{ }^{\circ} \mathrm{C}$ for $2-3 \mathrm{~h}$ under nitrogen gas. After the firing process, powders were washed with water to remove the residual flux and flux byproduct. Then, the product was washed with $0.5 \mathrm{M} \mathrm{HNO}_{3}$ solution for a clean and smooth particle surface.

The crystal structure and phase of the synthesized samples were analyzed by X-ray powder diffraction (XRD) with a wavelength of $\mathrm{Cu} K \alpha$. The structure was refined with the program GSAS. ${ }^{9}$ The peak shape was modeled with a pseudo-Voigt function. The fwhm (full width at half-maximum) was refined as a function of $2 \theta$, taking into account both Gaussian and Lorentzian broadening. The background was modeled as a 12-term polynomial function. Cell parameters, scale factor, and the background polynomial functions were free variables during refinements. The luminescence properties and aftergl ow phenomenon were studied by a SPEX Fluuorolog-2 spectrometer. The excitation source was a Xe lamp. All measurements were carried out at room temperature.

Figure 1 shows the comparison between the observed and calculated patterns as well as the difference curve

(3) Lange, H. Luminescent Europium Activated Strontium Aluminate. U.S. Patent 3,294,699.

(4) Blasse, G.; Bril, A. Philips Res. Rep. 1968, 23, 201.

(5) Palilla, F. C.; Levine, A. K.; Tomkus, M. R. J . Electrochem. Soc. 1968, 115,642 .

(6) Abbruscato, V. J . Electrochem. Soc. 1971, 118, 930

(7) Matsuzawa, T.; Aoki, Y.; Takeuchi, N.; Murayama, Y. J . Electrochem. Soc. 1996, 143, 2670.

(8) Murayama, Y.; Takeuchi, N.; Aoki, Y.; Matsuzawa, T. U.S. Patent 5,424,006.

(9) Larson A. C.; Von Dreele, R. B. Generalized Structure Analysis System (GSAS); Los Alamos National Laboratory Report LAUR 86748; Los Alamos National Laboratory: Los Alamos, NM, 1994. 
Table 1. Crystallographic Data of the $\left(\mathrm{Y}_{2-x-y} \mathrm{Ti}_{x} \mathrm{Mgy}_{y}\right) \mathrm{O}_{2} \mathrm{~S}(\mathrm{x}=\mathrm{y}=0.01)$ Phosphora $^{\mathrm{a}}$

\begin{tabular}{|c|c|c|c|c|c|c|}
\hline atoms & $\mathrm{x}$ & $y$ & z & \multicolumn{2}{|c|}{$U_{\text {iso }}\left(\AA^{2}\right) \times 100$} & occupancy \\
\hline $\mathrm{Y}$ & 0.666667 & 0.333333 & $0.28203(12)$ & \multicolumn{2}{|c|}{$1.863(18)$} & 0.9800 \\
\hline $\mathrm{Ti}$ & 0.666667 & 0.333333 & $0.28203(12)$ & \multicolumn{2}{|c|}{$1.863(18)$} & 0.0100 \\
\hline $\mathrm{Mq}$ & 0.666667 & 0.333333 & $0.28203(12)$ & \multicolumn{2}{|c|}{$1.863(18)$} & 0.0100 \\
\hline $\mathrm{S}^{3}$ & 0.000000 & 0.000000 & 0.000000 & \multicolumn{2}{|c|}{$\begin{array}{l}1.05(7) \\
1.95\end{array}$} & 1.0000 \\
\hline $\mathrm{O}$ & 0.666667 & 0.333333 & $0.6285(5)$ & \multicolumn{2}{|c|}{$2.09(13)$} & 1.0000 \\
\hline space group & cell parameters & reliability factors & \multicolumn{2}{|c|}{ bond angle (deg) } & \multicolumn{2}{|c|}{ interatomic distances $(\AA)$} \\
\hline $\mathrm{P} \overline{3} \mathrm{M} 1$ & $\begin{array}{l}a=b=3.78524(8) \AA \\
c=6.58809(14) \AA\end{array}$ & $\begin{array}{l}\mathrm{R}_{\mathrm{p}}=7.03 \% \\
\mathrm{R}_{\mathrm{wp}}=10.41 \% \\
\chi^{2}=1.69\end{array}$ & $\begin{array}{l}O-M-O \times 3 \\
O-M-O \times 3 \\
S-M-S \times 1 \\
S-M-O \times 6 \\
S-M-O \times 3 \\
S-M-O \times 3\end{array}$ & $\begin{array}{c}74.90(9) \\
113.47(3) \\
82.567(18) \\
78.52(7) \\
130.372(12) \\
154.73(10)\end{array}$ & $\begin{array}{l}M-O \times 3 \\
M-O \times 1 \\
M-S \times 3\end{array}$ & $\begin{array}{l}2.2635(10) \\
2.282(4) \\
2.8685(5)\end{array}$ \\
\hline
\end{tabular}

$\mathrm{a}=\mathrm{Y}, \mathrm{Ti}$, and $\mathrm{Mg}$.

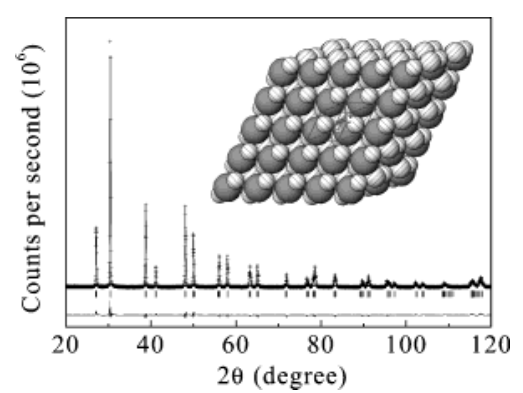

Figure 1. Rietveld fits to powder $X R D$ data for $\left(Y_{2-x-y} T_{x^{-}}\right.$ $\mathrm{Mg}_{\mathrm{y}} \mathrm{O}_{2} \mathrm{~S}(\mathrm{x}=\mathrm{y}=0.01)$. Experimental (crosses), theoretical (solid line), reflection positions (vertical bars), and difference between observed and calculated intensity (solid line at the bottom). U pper right, structure of $\mathrm{Y}_{2} \mathrm{O}_{2} \mathrm{~S}$. Yttrium (small balls), oxygen (medium balls), and sulfur (big balls).

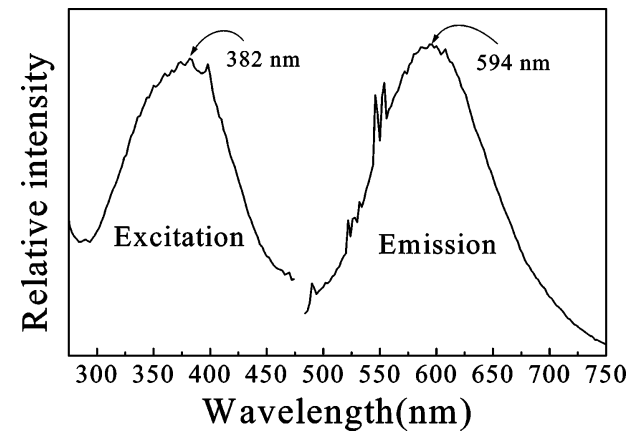

Figure 2. Emission and excitation spectra of the $\left(\mathrm{Y}_{2-x-y} \mathrm{Ti}_{\mathrm{x}}\right.$ $\mathrm{Mg}_{\mathrm{y}} \mathrm{O}_{2} \mathrm{~S}(\mathrm{x}=\mathrm{y}=0.01)$ phosphor.

of the $\left(\mathrm{Y}_{2-x-y} \mathrm{Ti}_{x} \mathrm{Mg}_{\mathrm{y}}\right) \mathrm{O}_{2} \mathrm{~S}(\mathrm{x}=\mathrm{y}=0.01)$ powder. The factors of the refinement are $R_{p}=7.03 \%, R_{w p}=10.41 \%$, and $\chi^{2}=1.69$, respectively. J udging from the XRD patterns and the refinement data, the $\left(\mathrm{Y}_{2-x-y} \mathrm{Ti}_{x} \mathrm{Mg}_{\mathrm{y}}\right) \mathrm{O}_{2} \mathrm{~S}$ $(x=y=0.01)$ phosphor has a hexagonal structure with the lattice constants of $a=b=3.78524(8) \AA$ and $c=$ 6.58809 (14) $\AA$. The upper right part of Figure 1 is the corresponding structure of $\left(\mathrm{Y}_{2-x-y} \mathrm{Ti}_{x} \mathrm{Mg}_{\mathrm{y}}\right) \mathrm{O}_{2} \mathrm{~S}(\mathrm{x}=\mathrm{y}=$ 0.01). Ti and $\mathrm{Mg}$ ions randomly substitute the position of yttrium in the $\mathrm{Y}_{2} \mathrm{O}_{2} \mathrm{~S}$ compound. The atomic parameters derived from the refinements are given in Table 1.

Figure 2 shows excitation and emission spectra of the $\left(\mathrm{Y}_{2-x-y} \mathrm{Ti}_{x} \mathrm{Mg}_{\mathrm{y}}\right)_{2} \mathrm{~S}(\mathrm{x}=\mathrm{y}=0.01)$ phosphor. The excitation maximum appears at $382 \mathrm{~nm}$ and emits luminescence with a peak wavelength of $594 \mathrm{~nm}$. The broad peaks of spectra indicate that the excitation and emission processes are caused by charge transfer transition. Figure 3 is the corresponding $\mathrm{CIE}$ chromaticity graph.

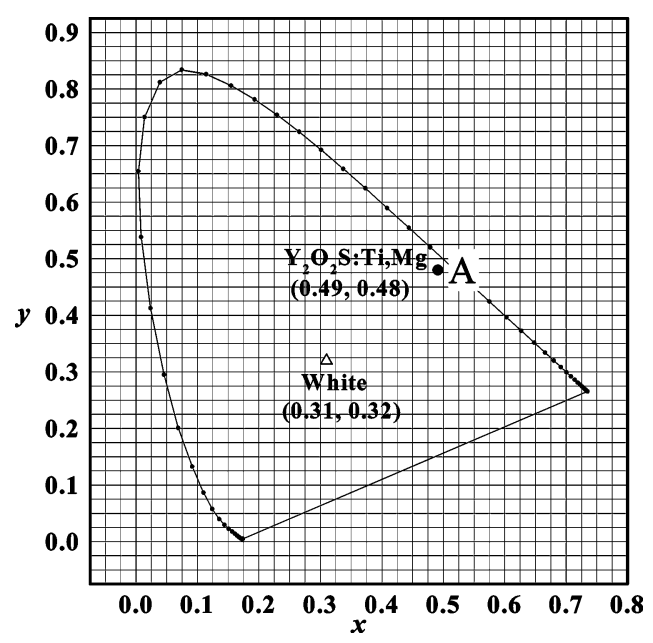

Figure 3. Chromaticity of the $\left(\mathrm{Y}_{2-x-y} \mathrm{Ti}_{x} \mathrm{Mg}_{\mathrm{y}}\right) \mathrm{O}_{2} \mathrm{~S}(\mathrm{x}=\mathrm{y}=0.01)$ phosphor.

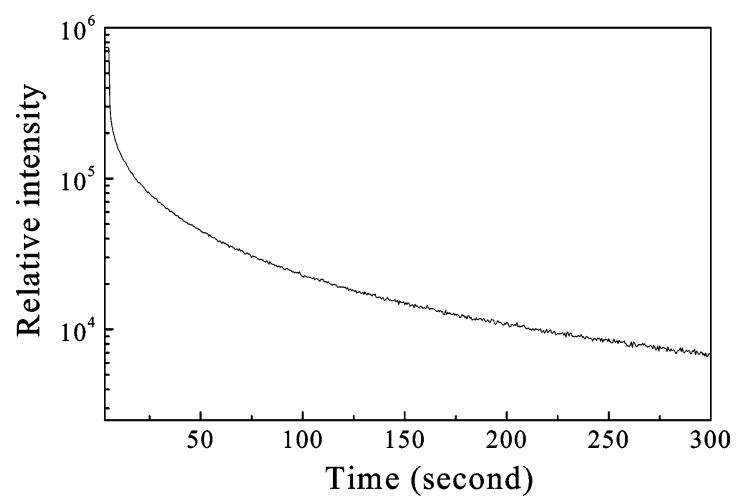

Figure 4. Persistent phosphorescence characteristics of $\left(\mathrm{Y}_{2-x-y} \mathrm{Ti}_{x} \mathrm{Mg}_{\mathrm{y}}\right) \mathrm{O}_{2} \mathrm{~S}(\mathrm{x}=\mathrm{y}=0.01)$ phosphor measured at $24^{\circ} \mathrm{C}$ after removal of the excitation source.

Point A with chromaticity coordination of $(0.49,0.48)$ in Figure 3 locates in the region of yellowish-orange color. Afterglow characteristics, after the removal of light excitation, are shown in Figure 4. It is obvious that the incorporation of the $\mathrm{Ti}$ and $\mathrm{Mg}$ ions gives rise to the $\left(\mathrm{Y}_{2-x-y} \mathrm{Ti}_{x} \mathrm{Mg}_{\mathrm{y}} \mathrm{O}_{2} \mathrm{~S}\right.$ phosphor with a yellowish-orange aftergl ow effect.

It was suggested that the persistence of phosphorescence and long decay time of $\mathrm{SrAl}_{2} \mathrm{O}_{4}: \mathrm{Eu}$,Dy phosphor are due to the trapping mechanism resulting from $\mathrm{Dy}^{3+}$ ions doping. ${ }^{7}$ Much research has been done to investigate the principle of the afterglow phenomenon. ${ }^{10-18}$ Single crystals, fibers, polycrystals, and thin films of the 
$\mathrm{SrAl}_{2} \mathrm{O}_{4}: \mathrm{Eu}$,Dy phosphor were synthesized for studying. Furthermore, photocurrent measurements, thermal luminescence, and theoretical calculations were adopted to investigate the mechanism of phosphorescent dynamics. Here, we propose that introduction of the $\mathrm{Ti}$ and

(10) Takasaki, H.; Tanabe, S.; Hanada, T.J . Ceram. Soc. J pn. 1996, $104,322$.

(11) Katsumata, T.; Nabae, T.; Sasajima, K.; Komuro, S.; Morikawa, T. J . Electrochem. Soc. 1997, 144, L243.

(12) Katsumata, T.; Nabae, T.; Sasajima, K.; Komuro, S.; Morikawa, T. J . Am. Ceram. Soc. 1998, 81, 413.

(13) Yamamoto, H.; Matsuzawa, T. J . Lumin. 1997, 72, 287.

(14) J ia, W.; Yuan, H.; Lu, L.; Liu, H.; Yen, W. M. J . Lumin. 1998, $76,424$.

(15) J ia, W.; Yuan, H.; Lu, L.; Liu, H.; Yen, W. M. J . Cryst. Growth 1999, 200, 179

(16) Yuan, H. B.; J ia, W.; Basun, S. A.; Lu, L.; Meltzer, R. S.; Yen, W. M. J . Electrochem. Soc. 2000, 147, 3154.

(17) Kato, K.; Tsutai, I.; Kamimura, T.; Kaneko, F.; Shinbo, K.; Ohta, M.; Kawakami, T. J . Lumin. 1999, 82, 213.

(18) Óhta, M.; Maruyama, M.; Hayakawa, T.; Nishijo, T. J . Ceram. Soc. J pn. 2000, 108, 284.
$\mathrm{Mg}$ ions to the $\mathrm{Y}_{2} \mathrm{O}_{2} \mathrm{~S}$ compound causes the formation of new el ectronic donating and accepting levels between the host lattice band gap. One of the two kinds of ions absorb energy and thermally transfer the excited electrons to the other kinds of ions which serve as trap centers. The trapping of excited electrons and thermally released processes caused the appearance of afterglow. A detailed study of the mechanism is underway.

In summary, a new yellowish-orange afterglow phosphor $\left(\mathrm{Y}_{2-x-y} \mathrm{Ti}_{x} \mathrm{Mg}_{\mathrm{y}}\right) \mathrm{O}_{2} \mathrm{~S}$ was synthesized by solid-state reaction under a nitrogen atmosphere. The introduction of $\mathrm{Ti}$ and $\mathrm{Mg}$ ions produced complex trap centers and resulted in the afterglow phenomenon.

Acknowledgment. The Chung-Shan Institute of Science \& Technology of the Republic of China under Grant N o. 91-2623-7-002-006 supported this work.

CM0344212 